\title{
Teatro e Prisão: o Núcleo Panóptico de Teatro e os resultados de um diálogo improvável, mas possível.
}

Vicente Concilio*

\section{Origens}

Quinze anos separam o encerramento da polêmica investida da produtora e atriz Ruth Escobar, que coordenou um processo teatral que durou oito meses dentro da Penitenciária do Estado, na capital paulistana, e o retorno de um programa que ousasse citar a palavra "teatro" naquele mesmo lugar.

A Penitenciária do Estado, ou PE, fazia parte de complexo do Carandiru, famoso presídio, o maior da América Latina e que chegou a comportar dez mil homens presos, demolido recentemente para, em seu lugar, ser construído uma área de lazer, o Parque da Juventude.

Durante aquele ano de 1980, Ruth e uma equipe de artistas, dentre os quais o diretor Roberto Lage, produziram um espetáculo com os presos, Aqui há Ordem e Progresso, que obteve grande repercussão por retratar de forma bastante aberta as condições de vida do homem preso: a dificuldade do retorno à sociedade após a prisão, o medo de perder a família, as relações de poder instituídas no espaço prisional são alguns exemplos da temática sobre a qual o espetáculo versava.

Vencida a censura interna do presídio, a peça conseguiu realizar diversas apresentações ao longo de um mês, e o grupo partiria para um segundo trabalho. No dia de Natal daquele ano, uma briga relacionada ao encerramento de uma partida de futebol iniciaria um processo que desembocaria em uma série de rebeliões. A direção da casa responsabilizou o grupo de teatro e seu poder "subversivo" pelo motim e acusou Ruth Escobar de incitar a rebelião e a proíbe de retomar seu trabalho, instaurando um processo contra

* Vicente Concilio: ator, diretor, professor de teatro. Atualmente realiza seu mestrado em Artes Cênicas na ECA/USP, na área de Teatro-Educação, com a diseertação "Teatro e Prisão: dilemas da liberdade artística em processos teatrais com população carcerária". 
ela. A resposta de Ruth foi rápida, com uma série de declarações à imprensa e a publicação de um livro, Dossiê de uma Rebelião, no qual ela documenta os textos produzidos pelo grupo, coleta críticas dos que assistiram ao espetáculo e organiza uma série de notícias relacionadas à rebelião produzidas pela imprensa.

A polêmica em torno de Ruth quase encerra um outro processo, mais antigo que o dela, coordenado pela atriz Maria Rita Freire Costa na Penitenciária Feminina da Capital (PFC), que acontecia desde 1978, denominado " $A$ Arte como Processo de Re-Criação em Presídios". Também apoiada por uma equipe de artistas, Maria Rita instaurou processos colaborativos de criação de espetáculos cujos temas eram trazidos pelas presas integrantes do processo, sendo estas responsáveis também pela criação das cenas e dos diálogos.

Este processo contou com a participação, até 1980, do ator e diretor Elias Andreatto e os dois últimos espetáculos ganharam registro e notoriedade ao serem filmados e transformados em documentários pelo cineasta Denoy de Oliveira. São eles Fala Só de Malandragem e Nós de Valor... Nós de Fato.

O documentário Fala Só de Malandragem foi vencedor do Festival de Brasília, na escolha do público, em 1985. Uma das detentas foi considerada "Melhor Atriz Coadjuvante", pois apesar de ser um documentário, ela aparecia como a personagem, uma vez que o espetáculo teatral era mostrado na íntegra no decorrer do filme.

A repercussão deste filme, embora apresentando o espetáculo quase três anos depois de sua estréia, foi um dos mais fortes argumentos contra a instituição da pena de morte no Brasil, tema de forte apelo na época, quando diversos setores da sociedade debatiam os principais tópicos a serem levados em consideração na Nova Constituição Brasileira, que seria aprovada pelo Congresso Nacional em 1988.

Esses trabalhos, tanto o de Ruth Escobar quanto o de Maria Rita encontraram, em plena ditadura militar brasileira, um espaço de criação de consciência crítica e de liberdade de opinião dentro de instituições punitivas por excelência. Construídas para reforçar o silêncio e a coerção, essas instituições penais foram palco de eventos cênicos que representaram os medos, os anseios e esperanças de homens e mulheres que não tinham muita saída que não esperar o fim de sua pena. E tiveram a oportunidade, a chance ou a sorte de realizarem algo por que se orgulharem em um presídio, onde não há muito espaço para a construção de nada, exceto o reforço da delinqüência. 
Em 1996, o projeto Teatro nas Prisões colocaria de novo a arte teatral dentro do Carandiru, agora fazendo uso das técnicas consagradas do CTO - Centro de Teatro do Oprimido, notadamente as técnicas de teatro-fórum, a fim de conscientizar a população carcerária acerca da prevenção e tratamento das DST (Doenças Sexualmente Transmissíveis) e da AIDS. Tratava-se do Projeto Drama - DST/AIDS. Mais tarde, o foco do projeto seria a questão dos Direitos Humanos, e aí as oficinas teatrais não seriam direcionadas somente aos presos, mas a todo o corpo funcional das unidades que receberam o Projeto Drama - Direitos Humanos em Cena.

O Projeto Teatro nas Prisões, então uma parceria da Fundação Prof. Dr. Manoel Pedro Pimentel de Amparo ao Preso - FUNAP (órgão vinculado ao Governo do Estado de São Paulo cuja missão institucional é promover trabalho, educação e cultura nos atuais 130 presídios que compõem o corpo principal da Secretaria de Administração Penitenciária do Estado de São Paulo) e o TIPP Center (Theater in Prison and Probation) da Universidade de Manchester, na Inglaterra, atingiu 34 unidades prisionais até seu encerramento, em dezembro de 2001.

Foi um longo processo cujos resultados ainda se fazem sentir nas instituições pelos quais o projeto passou, notadamente o fim do tabu da utilização do termo "direitos humanos" entre os funcionários das penitenciárias, que viam no termo com muito preconceito, entendendo que ele só dizia respeito aos "direitos dos manos".

É dentro desse processo de revitalização do debate acerca da qualidade de vida oferecida aos presos que, em 1998, um dos monitores de educação da FUNAP, integrante da equipe do Projeto Drama - DST/AIDS, consegue permissão para iniciar uma oficina de teatro dentro do Centro de Observação Criminológica, o COC, considerada ala de segurança máxima do Carandiru por abrigar presos jurados de morte pela natureza do crime que cometeram, o que os impedia de conviver em uma ala comum do presídio.

Tratava-se de uma unidade bastante rígida, nas quais ainda sobreviviam práticas pouco usuais no sistema como a ordem de os presos só caminharem pelos corredores em fila, com mãos para trás e cabeça baixa. Nesse ambiente, estrearia uma versão de "O Auto da Compadecida", encenada por homens presos e dirigida por Jorge Spínola, dando início ao que se configuraria em um projeto de "Montagem de Espetáculos" cuja continuidade vai resultar na criação do Núcleo Panóptico de Teatro. 


\section{A experiência no $\mathrm{COC}$}

Os três primeiros dos cinco espetáculos aconteceram no antigo Centro de Observação Criminológica (COC) do Complexo do Carandiru, presídio destinado à população masculina, em cumprimento de pena no regime fechado. Foi lá que em 1998 estreava O Auto da Compadecida, de Ariano Suassuna, em montagem que, por falta de elenco feminino, acabou colocando na boca de um novo personagem, o "Arcanjo Gabriel", as falas que deveriam ser atribuídas à figura da mãe de Jesus, que inclusive dá nome ao texto. Aparentemente, a solução não evitou que o intérprete ganhasse o apelido de "anjinho" no presídio, o que comprova o forte preconceito enfrentado pelo grupo de teatro não só pelo corpo dirigente quanto pelos próprios presos, que chamavam a atividade de "balé".

O fato é que após três apresentações dentro da própria unidade, o grupo conquistou a até então inédita possibilidade de apresentar o espetáculo na Penitenciária Feminina do Butantã, feito que abriu caminhos para que o grupo ganhasse o direito de mostrar, pela primeira vez na história do sistema penal paulista, um produto teatral, interpretado por homens presos, em um espaço distante das malhas penitenciárias: no TUCA, o Teatro da Pontifícia Universidade Católica de São Paulo, em junho de 1999, ao qual seguiram duas apresentações no Teatro Sérgio Cardoso, em agosto do mesmo ano, ambas com ampla cobertura pela imprensa escrita e televisiva.

Sobre a montagem Suassuna escreveu, em sua coluna no jornal Folha de São Paulo:

"Um deles (referindo-se a um dos presidiários) chegou a declarar: Em toda minha vida de crime eu nunca senti emoção tão grande quanto a de trabalhar no teatro. Pois posso garantir, a ele e aos outros, que minha emoção não foi menor. Lembrado das palavras do Cristo, o problema do castigo de uma pessoa humana sempre me angustiou; e, mesmo impotente como seja, sempre foi profunda a compaixão que eu sinto por qualquer condenado. Assim, fiquei contente ao ver que minha peça tinha levado um pouco de alegria (e talvez alguns momentos de reflexão) tanto aos atores que a encenaram quanto ao público de detentos que assistiu ao espetáculo. Por alguns momentos voltei a ser o menino que, na pequena cidade de Tapera, sertão da Paraíba, por ordem da tia e da mãe ia, com outros irmãos, visitar os presos da cadeia local, numa tentativa (também inócua, sei) de amenizar sua terrível e dolorosa condição".

O espetáculo seguinte continuou a se aprofundar no universo farsesco e popular da dramaturgia de Suassuna, com a montagem de A Pena e a Lei, 
que iniciou suas apresentações em 2000, e seguiu o caminho trilhado pela montagem anterior: apresentações dentro da própria unidade, apresentações em outros presídios e apresentações em outros espaços, chegando inclusive a levar a encenação para outras cidades que não a capital paulista, como Sorocaba.

Desta vez, entretanto, o grupo contou com a participação de uma "atriz convidada", Alexandra Tavares, que tinha então vinte anos e possibilitou uma enorme conquista para o processo, uma vez que o COC era considerado uma das instituições mais rígidas em todo o sistema.

Dessa forma, a possibilidade de permitir que uma jovem atriz participasse de ensaios, considerando obviamente que ela participaria de atividades que pressupunham contato físico e estudo coletivo para a elaboração das cenas, tudo isso ganhava alto valor simbólico, visto que consolidava não só a credibilidade artística do grupo, como ampliava sua responsabilidade para com a própria manutenção do teatro como atividade dentro da unidade penal.

Neste sentido, é imprescindível atribuir ao teatro o caráter agregador e coletivo inerente a seu exercício. Daí o peso de suas conquistas em um presídio, instituição total (GOFFMAN, 2001) que prima pela individualização dos que a ele estão submetidos, ao mesmo tempo em que promove uma forte massificação no trato desses seres com as regras, que em princípio todos estão submetidos de modo equânime, promovendo o que Goffman define como mortificação do eu (GOFFMAN, 2001).

A experiência do COC acaba quando o Complexo do Carandiru é desativado, e seus presos são transferidos, em sua maioria, para a Penitenciária do Tremembé, no final de 2001.

Mas durante todo aquele ano, o grupo constrói O Rei da Vela, de Oswald de Andrade, texto escrito em 1933, mas que só conheceria os palcos em uma montagem histórica realizada pelo Teatro Oficina em 1967, quando o contexto político do país renovaria os significados de um texto que, definitivamente, é um dos mais instigantes já produzidos pela nossa dramaturgia, e que conquista cada vez mais atualidade na medida em que as estruturas políticas, sociais e econômicas do Brasil parecem pouco ter mudado ao longo de todos esses anos que nos separam do autor modernista.

Esta montagem representou a conclusão de um longo processo de construção de sentidos para a possibilidade de inserção de práticas teatrais em presídios, ampliado justificativas que estivessem vinculadas simplesmente 
ao caráter "ressocializador" da arte. O discurso da ressocialização invariavelmente promoveria um julgamento das atitudes individuais de cada participante do processo, desviando a atuação da prática teatral de seu eixo mais interessante: o de promover um exercício coletivo de construção artística.

O Rei da Vela foi convidado, pelo próprio diretor do Teatro Oficina, Zé Celso Martinez Correa, a se apresentar no emblemático edifício que serve de palco, há mais de trinta anos, para as históricas encenações de um grupo que é referência na trajetória das lutas de resistência cultural do teatro brasileiro frente aos problemas financeiros e estéticos que fazem parte da identidade de nossos grupos teatrais.

A apresentação obteve grande repercussão e garantiu quase o dobro da capacidade do teatro, com o público lotando os três andares do espaço que compõe a área que lhe é destinada, no arrojado teatro projetado pela arquiteta italiana Lina Bo Bardi. Lá o público viu, além do espetáculo, aquilo que sempre ficou vedado pelas cortinas: cada um dos atores, enquanto recebia seus aplausos, ser algemado com brutalidade e, escoltados por dois policiais cada um, serem levados para o porta-malas do camburão que os levariam ao presídio.

\section{Mulheres de Papel}

Em 2002 e 2003, a construção de um novo espaço e de novos vínculos de reconhecimento artístico aconteceria na Penitenciária Feminina do Tatuapé (PFT), ao lado da famigerada unidade da Febem, famosa por promover, junto a seus 1.600 adolescentes detidos, as mais escandalosas rebeliões do sistema da Fundação Estadual para o Bem - Estar do Menor.

Ali, durante dois anos, entre muitas lutas por espaço para ensaios, que passaram da capela, que virou fábrica e exilou o teatro para o salão de beleza, do qual foi transferido para uma unidade intermediária entre uma fábrica de pirulitos e a entrada do pavilhão, ou seja, servia de passagem, o projeto só conseguiu finalmente ganhar um espaço próprio e apropriado para o trabalho com as cenas, uma sala do segundo andar do pavilhão destinado às unidades de trabalho, em meados do segundo ano de processo.

Como isso foi conquistado? Pela boa vontade do presídio, infelizmente, não foi. A FUNAP decidiu, pela primeira vez na história da instituição, pagar uma bolsa-salário às participantes (este caráter de ineditismo acontece por que o que está em jogo é uma ação cultural e educativa, sem caráter de produção de bens que não bens culturais e simbólicos, o que representou grande passo para a política educacional e cultural promovida pela FUNAP). 
Assim, o teatro foi alçado à categoria de "posto de trabalho", e não mais de "atividade cultural", o que elevou sensivelmente a credibilidade da atividade artística em relação aos apoios que vinha recebendo da direção e dos funcionários da unidade penal.

Nos meses de setembro e outubro, foram realizadas doze apresentações do espetáculo Mulheres de Papel, adaptação do texto Homens de Papel, de autoria de Plínio Marcos, cuja obra sempre esteve voltada para a exposição das mazelas sociais de nosso país e de suas personagens marginalizadas.

A cena, tomada por um grupo de catadoras de papel, decididas a promover uma greve contra os abusos que vinham sofrendo do comprador do material por elas recolhido do lixo, tem como conflito principal discussões na ordem dos limites entre as expectativas individuais e seu confronto com decisões de ordem coletiva, materializadas no embate entre o grupo e a personagem Nhanha, que não pretende aderir à paralisação pela necessidade de conseguir dinheiro para levar a filha ao médico.

Esta complexa relação entre decisões coletivas, por um lado, e opções individuais, por outro, acabavam por refletir o próprio processo de construção das regras que conduziam os ensaios e que, portanto, definiram o próprio processo de construção do grupo. Tratava-se de um relacionamento diferente do habitual, para as presas, com o conceito de regras. Até então, as regras não se apresentavam a elas como um corpo orgânico, passível de alterações em fluxo dinâmico a fim de atender às necessidades do grupo, e que só teriam sentido se realmente fossem obedecidas não por medo de punição, mas por serem essenciais ao pleno funcionamento dos ensaios.

O espetáculo foi visto por aproximadamente 1000 pessoas, dentre presas e público "de fora", composto por muitas pessoas que entravam em um presídio pela primeira vez, o que significava uma clara possibilidade de derrubada dos muitos muros que a sociedade erige em relação ao universo penal.

Entretanto, a despeito de toda a repercussão obtida pelo trabalho, o presídio decidiu proibir as apresentações para o público externo, alegando impossibilidade do setor disciplinar em revistar com a devida qualidade todas as pessoas que adentravam na unidade a cada apresentação.

A conclusão recaiu de forma drástica sobre o próprio trabalho, com a decisão da FUNAP em retirar o projeto Teatro nas Prisões da Penitenciária Feminina do Tatuapé, e representou um golpe muito duro para as participantes do processo. De qualquer forma, a decisão repercutiu em instâncias mais 
elevadas na hierarquia da Secretaria da Administração Penitenciária, que derrubou a diretoria responsável pela saída do projeto da unidade, o que não deixa de revelar a importância atribuída ao teatro por figuras importantes na implantação de políticas públicas destinada a população encarcerada.

\section{Muros}

Resulta então que a mais recente incursão do Núcleo Panóptico de Teatro ganhou a possibilidade de trabalhar não mais submetida às regras das unidades prisionais, mas fora delas. Desde março de 2004 o trabalho passou a ser realizado com dez presos em regime semi-aberto e dez ex-presidiários, além de um grupo de atores profissionais de diferentes formações.

O processo tomou como pontos de partida o conto O Muro, de Jean-Paul Sartre e cenas de $O$ Balcão, de Jean Genet, que se uniram ao trabalho de criação dos atores e do encenador a fim de produzir um forte discurso cênico cujo objetivo central era o de manifestar o valor da resistência diante da opulência dos opressores e da necessidade de se construir um apelo contra as formas de tortura, seja as que se encontram mascaradas em gestos assistencialistas, seja nas suas formas escancaradas e humilhantes, como agressões físicas e manifestações de força injustas, tão comuns no trato com os indivíduos encarcerados

O conto de Sartre, O Muro, trata do tema, tão caro ao existencialismo, da situação limite. Um grupo de revolucionários é torturado, das mais diversas formas, a fim de que se revele o paradeiro do líder do movimento. Transplantado para a nossa complexa realidade atual, quem seriam os revolucionários, quem seriam os torturadores?

Partindo destas indagações e realizando debates que acompanhavam o processo de improvisações, que procurava estabelecer a aquisição dos códigos e princípios da linguagem cênica e do trabalho de interpretação teatral, o grupo realizava instigante processo de elaboração de sentidos para as ações e diálogos escritos no texto, que ganhavam novas possibilidades a cada vez que iam para a cena.

Passaram pelo processo aproximadamente 50 pessoas, muitas das quais acabaram abandonando o trabalho à medida que conseguiam um emprego, ou simplesmente não se identificavam com a natureza da prática teatral. Com os presos em regime semi-aberto, a situação ficava bem mais complicada: suas vidas ainda estão submetidas à estrutura da prisão, e cada deslize por eles cometido, seja por chegarem atrasados à unidade prisional, seja por tentarem entrar na unidade carre- 
gando qualquer produto que Ihes é proibido portar, como peças de roupa ou alimentos, eles eram automaticamente desligados do trabalho.

São pequenos deslizes que a prisão transforma em grandes delitos, sobretudo pelo motivo de que o indivíduo em regime semi-aberto vive metade do tempo com a ilusão da liberdade, e briga por manter o máximo dela durante o tempo em que ainda ficará atrás das grades, provocando confusões por coisas que consideramos absolutamente banais, como o direito de levar uma revista para o quarto (no caso deles, para a cela).

De qualquer forma, o trabalho obteve grande repercussão graças ao fato de haver se transformado no último evento que possibilitaria ao público conhecer parte da antiga Casa de Detenção, o Carandiru, o mais famoso dos presídios, alçado a monumento da irresponsabilidade de nossos políticos para com o tratamento do preso, quando cenário do famoso massacre em que 111 homens foram assassinados pela tropa de choque da Polícia Militar, sob ordem do então governador Luiz Antonio Fleury Filho, no fim de 1992.

As oito apresentações tiveram lotação esgotada e o Núcleo, que recebeu o reconhecimento de instâncias públicas de financiamento, através da aprovação do trabalho do Núcleo Panóptico pela comissão da Lei de Fomento ao Teatro para a Cidade de São Paulo, Lei 13.279-02, seguiu apresentando o espetáculo em diversos locais durante todo o ano de 2005. Além disso, a continuidade do aperfeiçoamento dos artistas através de um novo processo de trabalho teatral resultou na escolha do próximo trabalho do grupo, que optou por se debruçar sobre o texto Marat-Sade, de Peter Weiss, com intenção de estrear em meados de 2006, sob direção da atriz Lígia Borges, uma das fundadoras do Núcleo.

\section{Sentidos do teatro na prisão}

Aparentemente, denominar uma proposta de trabalho em teatro e educação de "Projeto de Montagem de Espetáculos" parece reduzi-la a um simples processo de encenação pouco interessante em termos pedagógicos: aquele em que atores obedecem às marcações feitas por um diretor cuja concepção nasce de sua "genialidade" e não da interação entre um processo que englobe propostas trazidas por todos os artistas envolvidos.

Por outro lado, em um contexto em que as propostas envolvendo teatro estavam dominadas por uma abordagem das técnicas de teatro do oprimido que privilegiavam a utilização da cena como meio para transmissão de conteúdos referentes aos temas colocados em discussão (DSTs e Direitos Humanos), era importante deixar claro que a proposta de Jorge Spínola ex- 
ploraria outros aspectos das práticas em teatro e educação.

A frente de "Montagem de Espetáculos", dentro do Projeto Teatro nas Prisões, conquistou portanto um espaço para novas possibilidades de trajetória educacional, agora mais voltada para as relações entre a cena e as possíveis repercussões e buscas de sentido para um processo artístico, ou seja, fundamentado em princípios de liberdade de criação, e o regime punitivo de privação de (justamente!) liberdade.

Este paradoxo, fundamental entre os muitos outros com os quais se lida ao promover um exercício de criação teatral em uma prisão, está intrincado no cerne de todas as atividades enquadradas nas propostas "reabilitadoras" promovidas pelo presídio. Embora a maior parte dos esforços da instituição penal esteja voltada para o controle da massa encarcerada e para o combate a manifestações que abalem sua ordem interna, o discurso defendido pela prisão é outro, o de que sua ação está voltada para a transformação do infrator em cidadão responsável, mediante cumprimento da pena.

Sobre esta questão, Foucault, no célebre Vigiar e Punir (FOUCAULT, 2004) erige elaborada explanação, demonstrando que, paralelamente à consolidação da prisão como modelo punitivo que se sobressaiu no mundo dito civilizado, organizaram-se uma série de saberes a partir de discursos produzidos pelas mais diversas ciências (a arquitetura, a psicologia, o direito, a psiquiatria, a pedagogia, etc.). A soma desses discursos termina por elaborar a Criminologia, responsável fundamental para a construção do conceito moderno de delinqüência, que sobrepõe ao ato transgressor, portanto criminoso, o impulso transgressor, de tal forma que passa a se debruçar sobre o indivíduo, agora envolvido em uma série de laudos, exames e testes que vão ligá-lo eternamente a sua atitude penalizada.

Desta forma, não resta ao indivíduo penalizado, objeto da ação de todo aparato técnico-científico elaborado pelo saber penitenciário, outra alternativa que não carregar eternamente o estigma de ter sido preso, e sua vida será tolhida de toda sorte de possibilidades oferecidas aos "normais", de tal forma que não restem muitas alternativas que não o retorno ao mundo do crime. É por essa razão que no Brasil os índices de reincidência penal chegam ao número alarmante de $70 \%$.

Diante de toda sorte de estereótipos sociais e de visões deformadas dos indivíduos submetidos à prisão, o teatro promove, para além de todas as questões relativas ao desenvolvimento do potencial artístico daqueles que participam das atividades e se envolvem na construção do evento cênico, o momento da troca entre espectadores e artistas, concentrados justamente 
no período curto de tempo em que o espetáculo é apresentado e submetido ao aval da platéia.

Este momento, esperado ansiosamente durante todo o processo que leva à construção do espetáculo, catalisa uma série de expectativas produzidas pelos dois lados que compõem o momento da troca: os atores procurarão entregar o melhor de si e esperam que a platéia, por sua vez, saia surpreendida e enriquecida por haver desfrutado do resultado cênico de toda a experimentação que os atores vivenciaram a fim de chegar na encenação final.

O projeto Teatro nas Prisões e o Núcleo Panóptico de Teatro defenderam, inicialmente de forma sutil, a partir de textos que criticavam a estruturas que mantêm as desigualdades sociais de nosso país, e atualmente de forma mais escancarada, ao fazer uso de um texto que revela as estruturas de manutenção da ordem injusta que permanece embasando a política e manutenção das mazelas nacionais, a possibilidade de realização de espetáculos que construam notável qualidade artística e envolvimento real de todos os participantes na produção de um discurso cênico que irradie questionamento e sentidos diversos aos que tiverem possibilidade de apreciá-lo.

Para além do próprio processo teatral, e de todos os problemas que envolvam a produção de uma encenação dentro de presídios, tendo na população carcerária seus principais protagonistas, interessa ao Núcleo Panóptico o momento do encontro com o público, quando este, normalmente surpreendido pelo poder transformador da arte, reage emocionado à quebra da expectativa de assistir a um espetáculo com presos, e conhece uma face que não costuma associar a esse universo: a beleza e prazer da fruição de uma arte de resistência, que derruba preconceitos e constrói novas conotações a essas vidas encarceradas.

No caso específico da atuação do Núcleo Panóptico, não é raro que esta experiência ganhe outras conotações, uma vez que a platéia está ciente de que o espetáculo presenciado é composto pelo trabalho artístico de um grupo de pessoas ao qual se prefere manter a maior distância possível, uma vez que a segurança "aqui fora" parece ser proporcional ao número de pessoas trancadas "lá dentro".

Dessa forma, não é exagero defender que os aplausos, muitas vezes, não se dirigem apenas ao espetáculo, mas sobretudo ao fato de se presenciar um exercício autêntico de possibilidades inesperadas, uma vez que produzidas por prisioneiros, que durante algum tempo puderam habitar, no espaço mágico do teatro, outros territórios que não os submundos ao qual 
se convencionou a eles atribuir.

\section{Notas}

${ }^{1}$ A Lei de Fomento ao Teatro destina à produção teatral da cidade de São Paulo 6 milhões de reais, distribuídos em dois processos de seleção realizados no decorrer de cada ano. Os critérios de avaliação compreendem a análise da importância de se viabilizarem propostas cênicas que não pretendem se submeter a leis do mercado e que se preocupem em multiplicar e difundir a arte teatral por toda a cidade.

\section{Bibliografia}

COSTA, Maria Rita Freire. A Arte como Processo de Recriação em Presídios. Catálogo do Projeto. São Paulo, 1983.

ESCOBAR, Ruth. Dossiê de uma Rebelião. São Paulo, Global, 1982 (Coleção Passado e Presente).

FERNANDES, Rofran. Teatro Ruth Escobar: 20 anos de resistência. São Paulo, Global, 1985.

FOUCALT, Michel. Vigiar e Punir - Nascimento da Prisão. Petrópolis: Vozes, 2004.

FREIRE, Paulo e BETTO, Frei. Essa Escola Chamada Vida - Depoimentos ao Repórter Ricardo Kotscho. São Paulo, Ática, 1986.

ILANUD. Direitos Humanos em Cena: oficinas teatrais com a população prisional de São Paulo. Revista do ILANUD n.21. São Paulo, 2002.

GOFFMAN, Erving. Manicômios, Prisões e Conventos. São Paulo: Perspectiva, 2001.

MARCOS, Plínio. Homens de Papel e Barrela. São Paulo: Ed. Parma, 1976.

SUASSUNA, Ariano. Valquíria e o Carandiru. Folha de São Paulo, São Paulo, 13 jul. 1999. Caderno llustrada. 